\title{
Processes governing the flow redistribution in sharp river bends
}

\author{
W. Ottevanger ${ }^{\text {a,* }}$, K. Blanckaert ${ }^{\text {a,b,c,d }}$, W.S.J. Uijttewaal ${ }^{\text {a }}$ \\ ${ }^{a}$ Faculty of Civil Engineering and Geosciences, Delft University of Technology, Postbox 5048, 2600 GA Delft, The Netherlands \\ b ENAC, Ecole Polytechnique Fédérale, Lausanne, Switzerland \\ ' Institute of Freshwater Ecology and Inland Fisheries, Berlin, Germany \\ d State Key Laboratory of Urban and Regional Ecology, Research Center for Eco-Environmental Sciences, Chinese Academy of Sciences, Beijing, China
}

\section{A R T I C L E I N F O}

\section{Article history:}

Received 30 April 2010

Received in revised form 11 March 2011

Accepted 12 April 2011

Available online 5 August 2011

\section{Keywords:}

Meandering streams

Velocity redistribution

Curvature

Secondary flow

Topographic steering

Nonlinear mechanics

\begin{abstract}
A B S T R A C T
Insight is provided in hydrodynamic processes governing the velocity redistribution in sharp river bends based on simulations of three recent experiments by means of Blanckaert and de Vriend's (2003, 2010) reduced-order nonlinear model without curvature restrictions. This model successfully simulated the flow redistribution and the secondary flow in all three experiments. The results indicate that the flow redistribution is primarily governed by topographic steering, curvature variations and secondary flow, in a broad range of different configurations, including mildly to sharply curved bends, narrow to shallow bends, smooth to rough bends, bends with additional complexities such as horizontal recirculation zones or patches of riverbed vegetation. The relative importance of these three dominant processes is case dependent, and controlled by the parameters $C_{f}^{-1} H / B, R / B$ and streamwise curvature variations. The first parameter characterizes a river reach, whereas the second and third parameters are characteristics of individual bends. Major differences exist between the hydrodynamic processes in mildly and sharply curved bends. First, velocity redistribution induced by curvature variations is negligible in mildly curved bends, but the dominant process in sharp bends. This result is relevant, because most meander models are based on the assumption of weak-curvature variations. Second, nonlinear hydrodynamic interactions play a dominant role in sharp bends, where mild-curvature models overpredict the secondary flow and in some cases even falsely identify it as the dominant process governing the velocity redistribution, which leads to unsatisfactory flow predictions. The reduction in secondary flow strength provoked by the nonlinear hydrodynamic interactions is accompanied by a reduction in the transverse bed slope, which reduces the effect of topographic steering.
\end{abstract}

(c) 2011 Elsevier B.V. All rights reserved.

\section{Introduction}

The winding of single-thread rivers in their alluvial plane, known as meandering, has interested many scientists since the Renaissance (da Vinci, 1503-1508; Boussinesq, 1868; Fargue, 1868; Thomson, 1876; etc.) from various disciplines: meanders are studied by fluid dynamicists, morphologists, ecologists, geomorphologists, and petroleum engineers (see Camporeale et al., 2007, and the references therein). The recent attention for renaturalization projects has lead decision makers to consider the partial remeandering of previously trained rivers. Factors such as navigation and man-made infrastructure along the river set limits for the maximum migration of such rivers. Therefore, models that can predict the evolution of meandering rivers are required.

Mathematical models that are used to study meandering rivers generally consist of three interconnected components: i) a hydrodynamic component, ii) a channel bed morphology component and iii) a channel bank migration component. The hydrodynamic component

\footnotetext{
* Corresponding author.

E-mail address: w.ottevanger@tudelft.nl (W. Ottevanger).
}

describes the flow field and provides the shear stresses near the bed, which are the driving force behind the morphology component, which describes the adaptation of the riverbed, ultimately resulting in a sequence of alternating stable and migrating bars. Similarly the shear stresses near the bank are important for predicting the migration of the banks, which generally happens over longer time scales than the bed adaptation. The adaptation of the bed and the banks in turn influence the flow field and in this manner the system is interconnected. The focus of this paper will be on the hydrodynamic component.

Recently, Rüther and Olsen (2007) showed the feasibility of a threedimensional (3D) meander model by simulation of the 72-hour-lasting experiment of Friedkin (1945). The flow in their meander model was solved using Reynolds averaged Navier-Stokes equations with a k- $\varepsilon$ turbulence closure (Rodi, 1980), producing a detailed description of the flow. Their detailed hydrodynamic model provided all the shear stresses, which could be fed into the bed and bank adaptation components. Typical lengths of meandering rivers are much larger than the $40 \mathrm{~m}$ long tilting flume in Friedkin's (1945) experiment. Moreover, the time that is necessary for meandering rivers to migrate over the distance of a channel width is of the order of years instead of $72 \mathrm{~h}$ as in Friedkin's experiment. Therefore, it is expected that performing a simulation of a 
real river is not feasible using a detailed 3D hydrodynamic model as it would be computationally too expensive. Reduced-order hydrodynamic models, which are typically one-dimensional (1D) or two-dimensional (2D) models are computationally faster and have the advantage of being more insightful by clearly revealing the processes governing the flow redistribution. But they provide a less detailed description of the flow field and require a parameterization of 3D flow effects, which are known to play an important role in natural river bends.

An example of such a parameterization is the secondary flow (schematically indicated in Fig. 1), which is defined as the motion perpendicular to the streamwise flow. This secondary flow is related to the river planform and can primarily be expressed as a convolution function of the channel curvature. This secondary flow has two important effects on the flow redistribution. First, it induces a transverse component of the bed shear stress, which conditions the development of a transverse bed slope with increasing flow depth in outward direction (Olesen, 1987; Camporeale et al., 2007). This transverse bed slope scales with the inverse of the radius of curvature (Ikeda et al., 1981; Odgaard, 1981). According to Chézy's law, the depth-averaged velocity scales with the square of the flow depth, implying that higher/lower velocities will be attracted to the deeper/shallower parts of the cross section. This process is often called topographic steering (Dietrich and Smith, 1983; Blanckaert, 2010). Second, the secondary flow redistributes momentum, causing velocities to increase in outwards direction. The accompanying higher/lower sediment transport over the deeper/shallower parts strengthen the development of the transverse bed slope and lead to a positive feedback between the flow field and the transverse bed slope.

The secondary flow was first parametrized by van Bendegom (1947) and Rozovskii (1957), followed by many others (e.g. Engelund, 1974; Ikeda, 1975; de Vriend, 1977; Johannesson and Parker, 1989a). These models are invariantly based on mild-curvature assumptions, implying that $R / B$ and $R / H$ are sufficiently large and that the curvature radius varies slowly in streamwise direction. Here $R$ is the radius of curvature at the centerline, $B$ is the width and $H$ is the width-averaged flow depth (Fig. 1). In that case the interaction between the streamwise flow and the secondary flow is negligible, resulting in a secondary flow strength that is linearly proportional to the ratio $H / R$ and only a function of the roughness. It has been shown that mild-curvature secondary flow parameterizations considerably overestimate the secondary flow in moderately and sharply curved bends, because they neglect the nonlinear interactions between the streamwise flow and the secondary flow (de Vriend, 1981; Yeh and Kennedy, 1993; Blanckaert and de Vriend, 2003). Blanckaert (2009) has shown that the secondary flow does not increase when the curvature is increased in very sharp bends, and he called this process the saturation of the secondary flow.

Blanckaert and de Vriend $(2003,2010)$ developed and validated a nonlinear reduced-order hydrodynamic model that accounts for these nonlinear interactions and successfully simulates the saturation of the secondary flow. In its mild-curvature formulation, their model reduces to Johannesson and Parker's (1989b) linear model. Therefore, Blanckaert and de Vriend's model extends the parameterization of the secondary flow to sharply curved bends. Moreover, their model is neither restricted to mild curvatures nor to slow variations of the curvature in streamwise direction. Blanckaert and de Vriend (2010) predicted by means of a scaling analysis that these streamwise variations in curvature are a dominant driving force of the velocity redistribution in sharply curved bends. Blanckaert (2011) predicted by means of an analytical analysis for the case of axi-symmetric curved flow (infinite length bend, also referred to as fully-developed flow) that nonlinear hydrodynamic interactions are important in sharp openchannel bends.

Knowledge on the processes in sharply-curved bends is of practical relevance. Outer-banks in sharply-curved bends are particularly vulnerable to bank erosion. Moreover, cut-off events, which are an essential process in the long-term and large-scale meander dynamics, typically occur in sharply-curved bends. The aim of this paper is to extend foregoing investigations by enhancing the insight into the processes governing the velocity redistribution in sharply-curved open-channel bends, by addressing the following questions:

1. What are the dominant processes with respect to the velocity redistribution in sharply-curved open channels, and do they differ from the dominant processes in mildly-curved bends? Special attention is paid to the role of the streamwise variations in curvature. Sharp bends are typically relatively short and characterized by pronounced streamwise curvature variations. Linear models, which are based on the assumption of weak variations in curvature, are inherently unable to estimate the relevance of these variations.

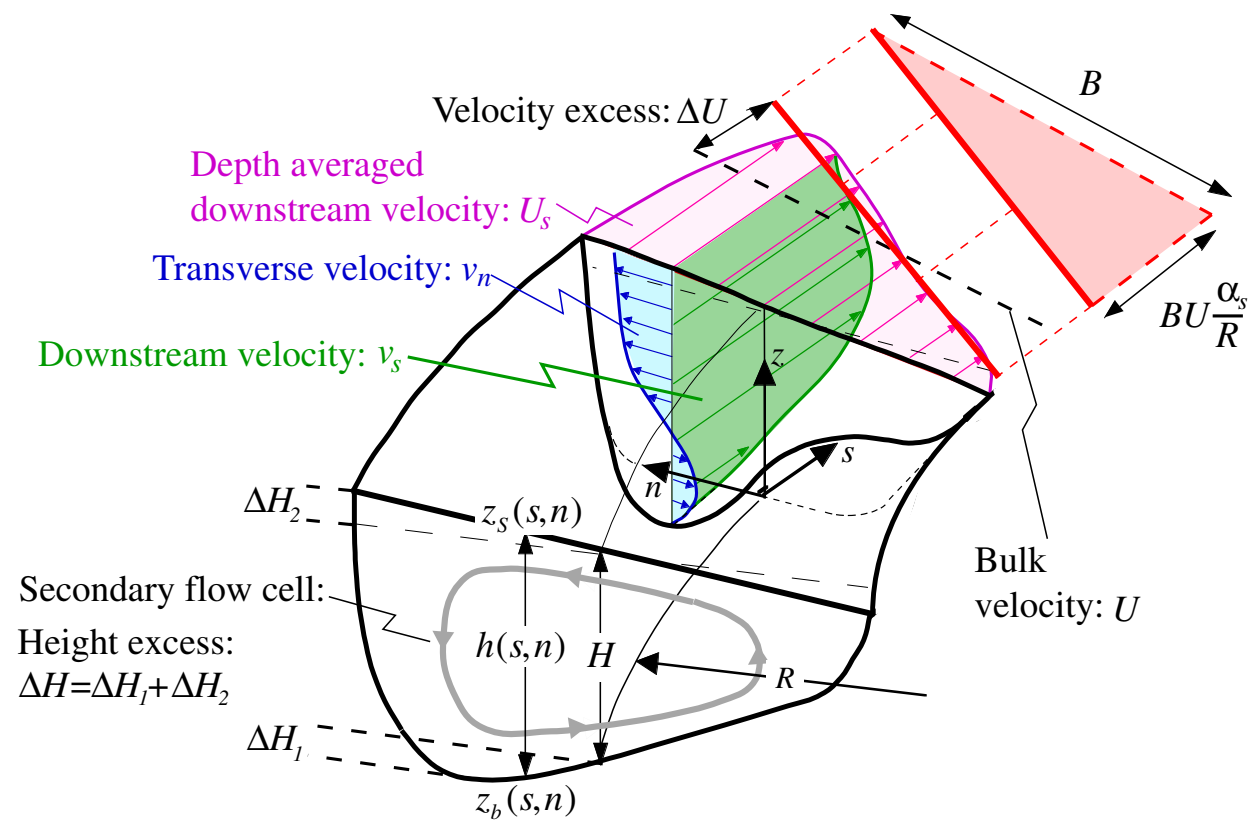

Fig. 1. Bend geometry with definition of variables.

(Modified from Blanckaert and de Vriend's (2003) Fig. 1). 
2. How important are nonlinear hydrodynamic interactions, and especially the saturation of the secondary flow, with respect to the velocity redistribution in sharp open-channel bends?

3. Is the velocity redistribution in sharply-curved laboratory flumes governed by the same processes as in sharp natural river bends characterized by additional processes such as horizontal recirculation zones or patches of vegetation?

These questions will be addressed by means of simulations performed with Blanckaert and de Vriend's $(2003,2010)$ model. This model will be briefly reported in Section 2; reference is made to Blanckaert and de Vriend $(2003,2010)$ for a more detailed and complete description. The questions will be addressed by investigating three configurations of sharply-curved open-channel bends with different characteristics. The first case concerns a sharply-curved narrow laboratory flume with rectangular cross-section and smooth boundaries. The second case concerns an even narrower sharp natural bend characterized by the near absence of secondary flow and a nearly flat bed topography. The third case concerns a sharp natural bend with gradually varying width, horizontal recirculation zones and patches of vegetation. These three cases are presented in Section 3. Section 4 focuses on the research questions.

\section{Reduced-order nonlinear hydrodynamic model}

Fig. 1 schematically defines the variables: $\Delta H$ and $\Delta U$ are the height and velocity excess at the outer bank w.r.t. their width-averaged values $H$ and $U$, respectively. The streamwise, transverse and vertical coordinates are given by $s, n$ and $z$ respectively. The three dimensional velocity is denoted by $v_{j}$, where the subscript $j$ refers to the component in the direction of the respective coordinate $s, n$, or $z$. In a similar way, $U_{j}$ is the depth averaged flow in $s$ or $n$ direction. The water and bed levels are given by $z_{s}$ and $z_{b}$, respectively. The centerline radius of curvature $R$ is positive (negative) for right (left) turning bends. Blanckaert and de Vriend's (2003) nonlinear hydrodynamic model is based on a reduction of the three-dimensional flow equations by means of profile functions with one degree of freedom for the transverse distributions of the depth-averaged streamwise velocity $U_{s}$ and the local depth $h$ :

$U_{s} \approx U\left(1+\frac{n}{R}\right)^{\alpha_{s} \text { first-order }} \stackrel{\text { approximation }}{\approx} U_{s} \approx U\left(1+\frac{\alpha_{s}}{R} n\right)$.

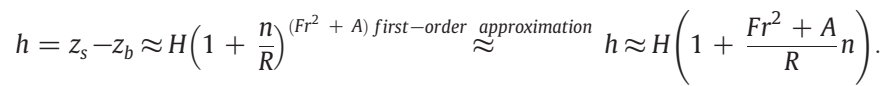

The degree of freedom in Eq. (1) is represented by the dimensionless number $\alpha_{s}$. Values of $\alpha_{s}=-1$ and $\alpha_{s}=1$ correspond to potential and forced vortex distributions, respectively (cf. Vardy, 1990; Blanckaert and de Vriend, 2003, Fig. 7). The square of the dimensionless Froude number, $\mathrm{Fr}^{2}$, parameterizes the transverse inclination of the water surface (often called superelevation). The so-called scour factor $A$ (Engelund, 1974; Zimmermann and Kennedy, 1978; Odgaard, 1981) parameterizes the transverse bed level gradient and is typically between 2.5 and 6 in natural open-channel bends (Ikeda et al., 1981; Odgaard, 1981). Obviously the adoption of transverse profile functions will only allow describing processes that occur on a length scale that is larger than the channel width. But the adoption of such simplified transverse distributions does not preclude the model to account for nonlinear processes.

Using the above parameterizations, Blanckaert and de Vriend's $(2003,2010)$ reduced-order nonlinear model describes the velocity redistribution in open-channel bends by means of the following nonlinear relaxation equation in $\alpha_{s} / R$ :

$\lambda_{\alpha s / R} \frac{\partial}{\partial s}\left(\frac{\alpha_{s}}{R}\right)+\frac{\alpha_{s}}{R}=F_{\alpha s / R}$

where the factor $\lambda_{\alpha s / R}$ is the flow adaptation length, and the system is subject to the forcing term $F_{\alpha s / R}$. The adaptation length $\lambda_{\alpha s / R}$ is defined as:

$\lambda_{\alpha s / R}=\frac{1}{2} \frac{H}{\psi C_{f}}\left(1-\frac{m}{12} \frac{\alpha_{s}+1}{R} \frac{B^{2}}{R}\right)$

where $C_{f}$ parameterizes the straight channel roughness, and the parameter $\psi$ (provided by Blanckaert and de Vriend, 2003, 2010; Blanckaert, 2009), parameterizes additional curvature-induced friction losses. The variable $m$ is a binary integer, which is set to 1 in the nonlinear model and to 0 in the mild-curvature formulation of the model. The forcing $F_{\alpha s / R}$ is described as:

$$
\begin{aligned}
F_{\alpha S / R}= & \frac{1}{2} \frac{F r^{2}+A-1}{R} \\
& -\frac{1}{2} \frac{H}{\psi C_{f}} \frac{\partial}{\partial s}\left(\frac{1}{R}\right)\left(1-\frac{m}{6} \frac{B^{2}}{R^{2}}\right) \\
& +\frac{6}{\psi C_{f}} \frac{H}{B^{2}} \frac{\left\langle v_{s} v_{n}\right\rangle}{U^{2}}\left(1+\frac{m}{12} \frac{\left(F r^{2}+A+3\right) B^{2}}{R^{2}}\right) \\
& +\frac{m}{24} \frac{H}{\psi C_{f}} \frac{B^{2}}{R^{2}} \frac{\partial}{\partial s}\left(\frac{F r^{2}+A}{R}\right)
\end{aligned}
$$

It clearly displays the processes governing the velocity redistribution. Its first line (I) in Eq. (5) relates to the transverse gradient of the water depth (cf. Eq. (2)) i.e. the effect of topographic steering (Nelson, 1990; Blanckaert, 2010). The second line (II) is related to streamwise changes in channel curvature. This term will be shown to be of predominant importance in sharply-curved bends and merits therefore some further explanation. The transverse tilting of the water surface (also called superelevation) is in first approximation given by $\partial z_{s} / \partial n \approx F r^{2} H / R$. Streamwise changes in $\partial R^{-1} / \partial s$ will thus lead to streamwise variations in the transverse tilting of the water surface that are accompanied by variations in the streamwise water surface gradient. An increase in curvature, for example, $\partial R^{-1} / \partial s>0$, will lead to an increase in the transverse tilting of the water surface. As a result, the streamwise water surface gradient will decrease/increase in the outer/inner part of the cross-section, leading to flow deceleration/ acceleration and flow redistribution. The third line (III) relates to the redistribution of the streamwise velocity by the secondary flow and the final line (IV) relates to streamwise changes in the transverse bed and water surface gradients. The brackets \langle\rangle represent depth-averaged values.

The velocity redistribution by the secondary flow, represented by $\left\langle v_{s} v_{n}\right\rangle / U^{2}$ is obtained from the following equation:

$\lambda \frac{\partial}{\partial s}\left\{\frac{\left\langle v_{s} v_{n}\right\rangle}{U^{2}}\right\}+\frac{\left\langle v_{s} v_{n}\right\rangle}{U^{2}}=\frac{\left\langle v_{s} v_{n}\right\rangle_{\infty}}{U^{2}}$

where $\lambda$ is the adaptation length defined in Johannesson and Parker (1989a) (cf. Blanckaert and de Vriend, 2010). The expression on the right hand side of Eq. (6) denotes the value obtained for axi-symmetric flow and is computed as follows:

$\frac{\left\langle v_{s} v_{n}\right\rangle_{\infty}}{U^{2}}=\frac{\left\langle v_{s} v_{n}\right\rangle_{\infty}}{\left\langle v_{s} v_{n}\right\rangle_{0}} \frac{\left\langle v_{s} v_{n}\right\rangle_{0}}{U^{2}} \stackrel{\text { Figure }}{=}{ }^{2} f c t(\beta) \frac{\left\langle v_{s} v_{n}\right\rangle_{0}}{U^{2}}$.

The index 0 indicates linear-model solutions, which grow linearly with the ratio $H / R$ and uniquely depend on the friction factor $C_{f}$ (e.g. 


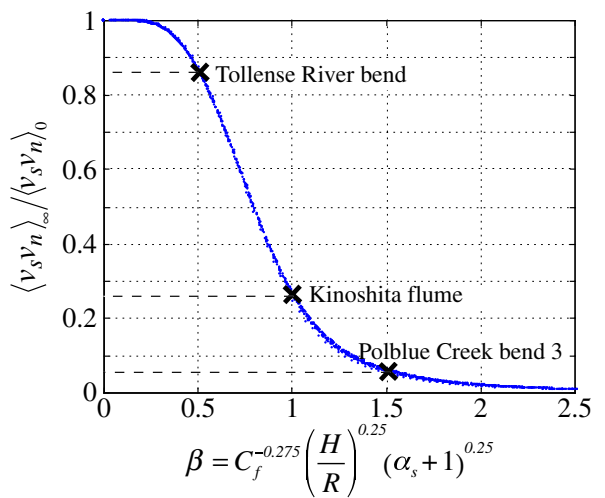

Fig. 2. Solution of Blanckaert and de Vriend's (2003) nonlinear model in the form of correction coefficient to-be-applied to the linear model solutions. The indices " 0 " and " $\infty$ " indicate linear and non-linear model solutions respectively. The values of the bendaveraged $\beta$ (Eq. (8)) from Table 1 are included to illustrate the effect of nonlinear hydrodynamic interactions on the secondary flow strength in the three different cases. Modified from Blanckaert and de Vriend (2003).

van Bendegom, 1947; Rozovskii, 1957; Engelund, 1974; Ikeda, 1975; de Vriend, 1977; Johannesson and Parker, 1989a). The nonlinear hydrodynamic interactions between the secondary flow and the streamwise flow are parameterized by means of the correction factor $\left\langle v_{s} v_{n}\right\rangle_{\infty} /\left\langle v_{s} v_{n}\right\rangle_{0}=f c t(\beta)$, which uniquely depends on the so-called bend parameter (Blanckaert and de Vriend, 2003):

$\beta=C_{f}^{0.275}\left(\frac{H}{R}\right)^{0.5}\left(\alpha_{s}+1\right)^{0.25}$

Fig. 2 provides the graphical solution of the correction factor $f c t(\beta)$, which is obtained by the model of Blanckaert and de Vriend (2003).

Inclusion of the correction factor $f c t(\beta)$ makes the variables $\alpha_{s} / R$ and $\left\langle v_{s} v_{n}\right\rangle / U^{2}$ mutually dependent according to Eqs. (3), (5), (7) and (8), indicating the nonlinearity of the hydrodynamics. A mild- curvature formulation is obtained by setting $m=0$ (Eqs. (4) and (5)), setting $f c t(\beta)=1$ (Eqs. (6) and (7)), and neglecting additional curvature-induced friction losses $(\psi=1)$. This mild-curvature formulation is identical to the linear model of Johannesson and Parker (1989b). Comparison of Blanckaert and de Vriend's model without curvature restrictions to the model of Johannesson and Parker (1989b) therefore reveals the influence and relevance of nonlinear hydrodynamic effects. Extensions and improvements of Johannesson and Parker's model have been proposed by e.g. Imran et al. (1999), Zolezzi and Seminara (2001) and Bolla Pittaluga et al. (2009). Comparison to these models would lead to similar results, however, because they are all based on the assumptions of mild curvature and weak curvature variations (a comparison between these models is reported in Blanckaert and de Vriend, 2010).

\section{Investigated sharp open channel bends}

\subsection{Kinoshita flume}

The first investigated case is the laboratory experiment carried out and reported by Abad and Garcia (2009) (Fig. 3 and Table 1). Their flume consists of seven consecutive bends of alternating direction, which centerline curvature is described by the so-called "Kinoshita curve" (cf. Parker et al. (1983)):

$$
\frac{1}{R}=-\frac{2 \pi}{\lambda} \theta_{0}\left\{\cos \left(\frac{2 \pi}{\lambda} s\right)-3 \theta_{0}^{2}\left[J_{s} \sin \left(3 \frac{2 \pi}{\lambda} s\right)+J_{f} \cos \left(3 \frac{2 \pi}{\lambda} s\right)\right]\right\}
$$

The terms between square brackets cause an asymmetrical form of the curve, whereas the first term in the right-hand-side represents the family of symmetric sine-generated curves defined by Leopold and Wolman (1960). These curves are a kind of averaged idealized representation of the planform of natural meandering rivers. Abad and Garcia (2009) adopted a maximum angular amplitude of $\theta_{0}=110^{\circ}$, which is characteristic of sharp bends close to cut-off, an arc wavelength of $\lambda=10 \mathrm{~m}$, as well as values of the skewness and

a) Kinoshita flume overview

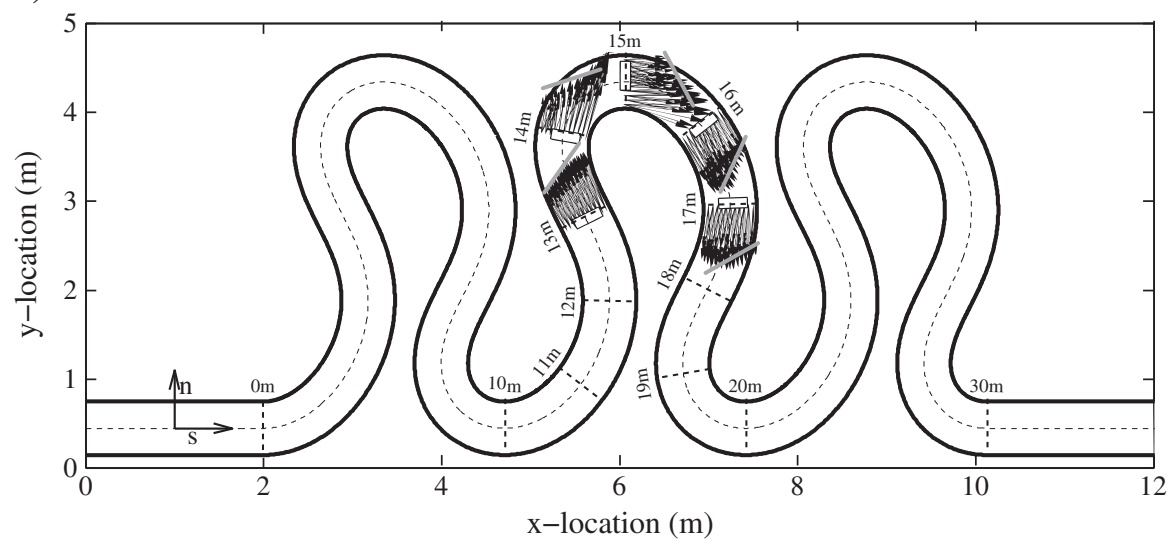

b) water level (m)

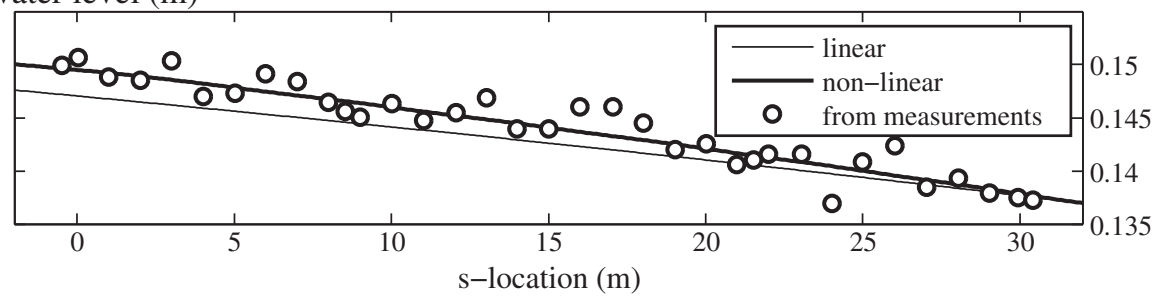

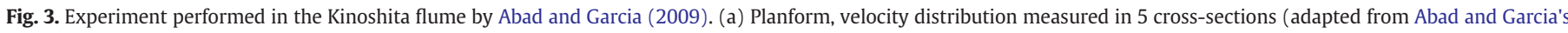

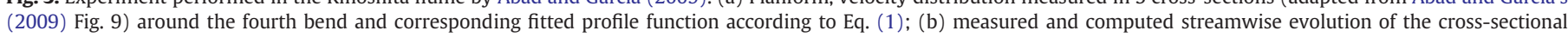
averaged flow depth $H$. 
Table 1

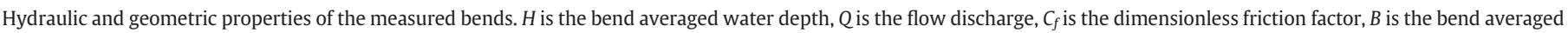

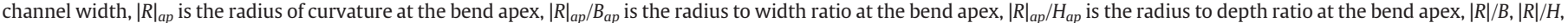
$C_{f}^{-1} H / B$ and $C_{f}^{-1} H /|R|$ bend averaged scaling parameters and $\beta$ is the bend averaged bend parameter (Eq. (8)).

\begin{tabular}{|c|c|c|c|c|c|c|c|c|c|c|c|c|}
\hline Case & $H[m]$ & $Q\left[m^{3} s^{-1}\right]$ & $C_{f}$ & $B[m]$ & $|R|_{a p}[m]$ & $|R|_{a p} / B_{a p}$ & $\left|R_{a p}\right| / H_{a p}$ & $|R| / B$ & $|R| / H$ & $C_{f}^{-1} H / B$ & $C_{f}^{-1} H /|R|$ & $\beta$ \\
\hline Kinoshita flume & 0.143 & 0.025 & 0.0048 & 0.6 & 0.72 & 1.2 & 5 & 2.4 & 10 & 50 & 21 & 1.0 \\
\hline Polblue Creek & 0.65 & 0.3 & 0.005 & 1.5 & 1.6 & 1.05 & 2.4 & 3 & 7 & 87 & 29 & 1.56 \\
\hline Tollense River & 1.5 & 1.48 & 0.03 & 19.1 & 16.4 & 0.7 & 9.2 & 1.42 & 17.3 & 2.6 & 2 & 0.53 \\
\hline
\end{tabular}

flatness of $J_{s}=1 / 132$ and $J_{f}=1 / 192$, respectively. The flume had a rectangular cross section with a constant width of $B=0.6 \mathrm{~m}$ and smooth boundaries parameterized by a friction factor of $C_{f}=0.0048$. The average flow depth in the experiment was $0.143 \mathrm{~m}$. The smooth boundaries, flat bed, narrow cross-section $(B / H \approx 4)$, low values of the ratios $R_{a p} / B_{a p}=1.2$, and $R_{a p} / H_{a p}=5\left(R_{a p}\right.$ is the centerline radius of curvature in the bend apex), indicate that this is a very sharply curved bend. Although such bend characteristics will rarely be encountered in nature (Blanckaert, 2011, Table 2 and its discussion), this case is an appropriate test case for the objectives of the present paper.

Fig. 3 shows the velocity distribution measured in the flume. Due to the change in direction between successive bends, the velocity distribution at the bend entrance is inwards skewed (velocities decrease from the inner bank towards the outer bank). This inwards skewed velocity distribution gets more pronounced in the region of strong curvature increase between the bend entrance and the bend apex. Downstream of the apex, outwards velocity redistribution is discernable, which results in an outwards skewed velocity distribution at the bend exit. Fig. 3 also shows the transverse profile functions with one degree of freedom that have been fitted to the experimental data according to Eq. (1). These profiles satisfactorily represent the global features of the velocity redistribution through the bend.

This experiment was simulated by means of the nonlinear hydrodynamic model as well as its mild-curvature formulation (Section 2). At the inflow of the flume, a uniform velocity distribution $\left(\alpha_{s}=0\right)$ was imposed without secondary flow. Futhermore a constant discharge was imposed upstream (see Table 1). The measured flow depth at the end of the flume was imposed as boundary condition at the flume exit. The streamwise water level is part of the model solution (see Fig. 3(b)). The difference between the linear and non-linear model solutions can be explained by the additional curvature induced friction losses parametrized by $\psi$ (see Eqs. (4) and (5)).

\subsection{Polblue Creek Bend 3}

The second investigated case is the sharply curved bend number 3 in the Polblue Creek, Barrington Tops National Park, New South Wales, Australia ( $31^{\circ} 57^{\prime} 20.33^{\prime \prime} \mathrm{S}, 151^{\circ} 24^{\prime} 42.90^{\prime \prime} \mathrm{E}$ ), which was investigated by Nanson (2010). A schematic overview of the bend is given in Fig. 4(a). Nanson (2010) performed flow measurements in the seven crosssections crs1 to crs7 shown in Fig. 4. The radius of curvature and the width of the bend have been estimated by digitizing the coordinates of the centerline and the banklines. The curvature radius, for example, is obtained from the mathematical definition of curvature (e.g. Legleiter and Kyriakidis, 2006) as:

$\frac{1}{R(s)}=\frac{x(s)^{\prime} y(s)^{\prime \prime}-x(s)^{\prime \prime} y(s)^{\prime}}{\left[x(s)^{\prime 2}+y(s)^{\prime 2}\right]^{3 / 2}}$

where $s$ is the intrinsic coordinate along the centerline, and $(x, y)$ are the coordinates of the centerline in an arbitrary Cartesian reference system. The centerline radius of curvature at the apex was found to be about $R_{a p}=1.6 \mathrm{~m}$, which is only slightly more than the average width of about $B=1.5 \mathrm{~m}$. The width varied slightly through the bend (Fig. 4(e)). The average flow depth in the bend was about $0.65 \mathrm{~m}$. The measured flow depth in cross-section crs6 was substantially lower (Fig. 4(d)), which is mainly due to the presence of a riffle in that cross-secton (Nanson, 2010) and a slightly increased width (Fig. 4(c)). This riffle could be due to the presence of a stable surface layer (e.g. a non-erodible layer). Fig. 4(b) illustrates the morphology of this narrow and deep peatland channel. The banks are quasi-vertical due to root reinforcement. From literature we find the following friction factor for bend 3 in the Polblue Creek, namely $\mathrm{Cf}=0.02$ (Nanson, 2010) and $\mathrm{Cf}=0.005$ (Nanson et al., 2010, Table 1: measurement P6 just downstream of bend 3). Nanson (2010) only assumes this value while in Nanson et al. (2010) the friction factor is analyzed in more detail along the Polblue Creek. Therefore, we believe that $\mathrm{Cf}=0.005$ given in Nanson et al. (2010) characterizes the friction factor in the Polblue Creek. Most notable are the absence of a point bar and the quasi-horizontal bed, which cannot solely be explained by the limited sediment supply, but must be related to the hydrodynamic forcing. Fig. 4(b) also shows the transverse profile functions with one degree of freedom that have been fitted to the measured bed topography according to Eq. (2), whereas Fig. 4(c) shows the corresponding evolution through the bend of the scour factor $A / R$. As mentioned before, these profiles are not intended to represent the local morphological features, but only the features occurring on a spatial scale larger than the channel width. The ratios $R_{a p} / B_{a p}=1.05$ and $R_{a p} / H_{a p}=2.4$ and the very narrow cross-sections indicate that this is a very sharply curved bend. In spite of this very sharp curvature, Nanson's (2010) measurements revealed that there was hardly any secondary flow throughout the bend, which complements the observation of the quasi-horizontal bed topography. Fig. 4(a) shows the velocity distribution measured by Nanson (2010). The velocity is about uniform over the width at the bend entrance. Similar to the velocity redistribution in the Kinoshita flume, the velocity skews inwards between the bend entrance and the bend apex, and subsequently skews outwards. In general, however, the skewing of the velocity profiles is weak and the distributions are remarkably uniform. Fig. 4(a) also shows the transverse profile functions with one degree of freedom that have been fitted to the experimental data according to Eq. (1). These profiles satisfactorily represent the global features of the velocity redistribution through the bend.

For this case the simulation was done imposing the measured velocity distribution based on Eq. (1) and velocity redistribution caused by secondary flow was imposed at the upstream boundary as $\left\langle v_{s} v_{n}\right\rangle_{\infty} / U^{2}=f c t\left(\beta\left(\alpha_{s, c r s 1}\right)\right) \cdot\left\langle v_{s} v_{n}\right\rangle_{0} / U^{2}$. The present simulations took into account the gradual variations of the width and depth by means of the smoothed interpolation curves shown in Fig. 4(d) and (e). The cross-sectionally averaged streamwise velocity subsequently follows as the discharge $Q$ along the reach is considered to be constant.

\subsection{Tollense River}

The third investigated case considers a meander bend in the Tollense River, Germany $\left(53^{\circ} 37^{\prime} 50.00^{\prime \prime} \mathrm{N}, 13^{\circ} 15^{\prime} 12.28^{\prime \prime} \mathrm{E}\right)$, which has been investigated by a team of the Leibniz-Institute of Freshwater Ecology and Inland Fisheries (IGB, Berlin, Germany) (Schnauder and Sukhodolov, 2011). The Tollense bend is schematically shown in Fig. 5. This bend is characterized by additional complexities in the form of horizontal recirculation zones, which are found at crs3 (outer bank) and at crs4 (inner bank). Schnauder and Sukhodolov (2011), computed the friction factor from the water slope as $C_{f} \approx 0.086$. Local values of friction factor were also derived from the vertical profiles of point measurements of 
a) Polblue Creek bend 3 overview

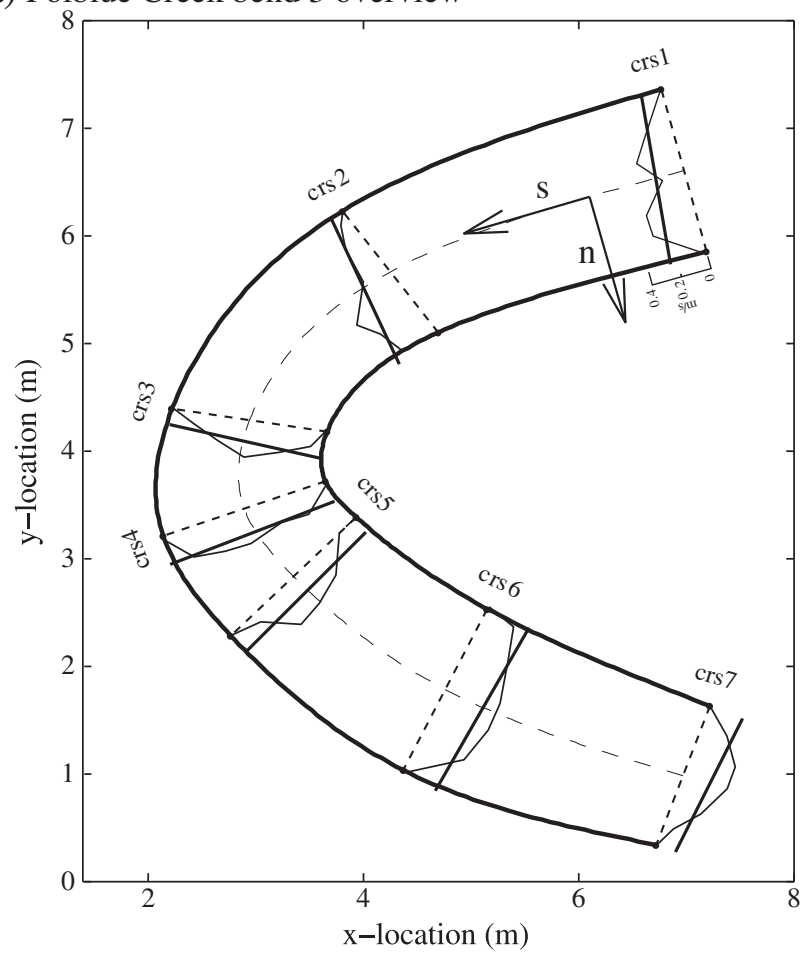

c) $A / R(1 / \mathrm{m})$

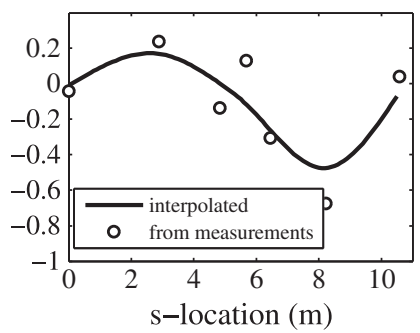

d) channel depth $H(\mathrm{~m})$

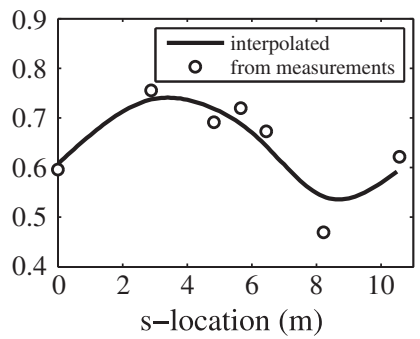

b) bed-elevation (m)
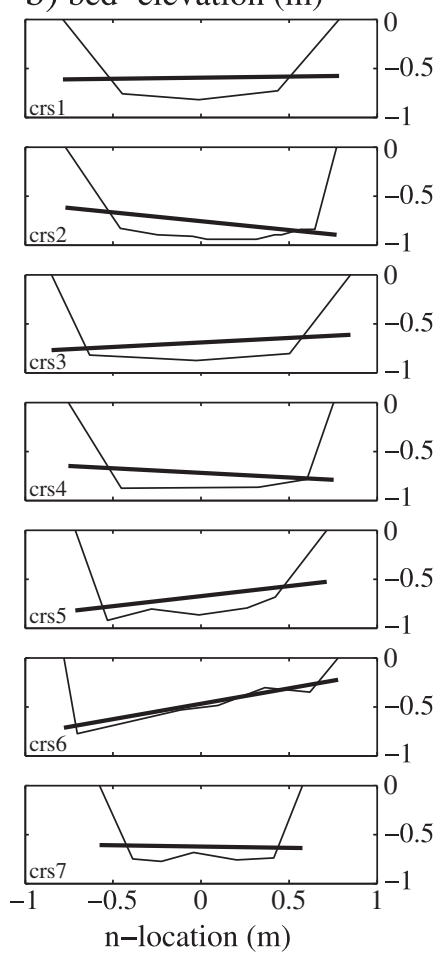

e) channel width $B(\mathrm{~m})$

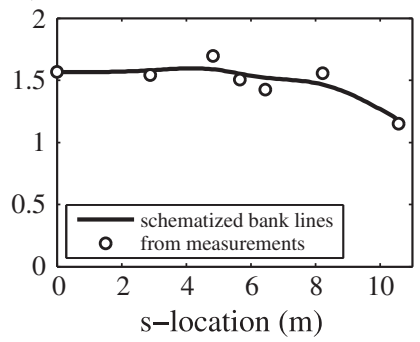

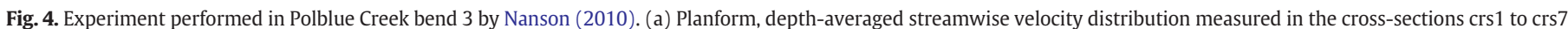

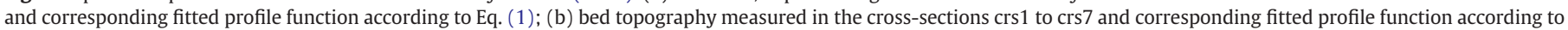

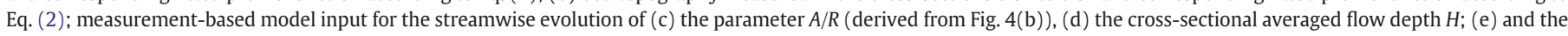
width (at the water surface)

velocity and Reynolds shear stresses. At locations without riverbed vegetation, the stress profiles were linearly extrapolated to the bed level to yield the bed shear stress. Where vegetation was abundant, the measured peak stress in the water column associated with the top of the vegetation canopy was taken as reference to determine the friction factor. The patchiness of the riverbed vegetation can be recognized in the spatial variations of the friction factor through the bend (Fig. 5(f) and Schnauder and Sukhodolov, 2011). The average friction factor found using the point measurements of velocity and Reynolds shear stresses is $C_{f}=0.03$ which is lower than the value obtained from the water slope. This difference can be explained because of the losses from the horizontal mixing layers and the topographic steering effects which cannot be captured using a model with a single degree of freedom for the bed-elevation $(A)$. Furthermore, the varying water depth along the bend and the low streamwise velocity $(U=0.05 \mathrm{~m} / \mathrm{s})$ introduce an added uncertainty for the correct determination of the friction factor from the water slope. We believe that the friction factor determined from point measurements of velocity and the Reynolds stresses is a more accurate representation of the bed-friction and therefore this value will be used in the simulation. The centerline radius of curvature and the width were estimated according to the same method applied for the Polblue Bend. The centerline radius of curvature at the apex was found to be about $R_{a p}=16.4 \mathrm{~m}$, which is smaller than the average width of about $B=19.1 \mathrm{~m}$. The width varies through the bend (Fig. 5) and attains maximum values in the cross-sections where outer-bank flow separation occurs (crs3) and at the bend apex (crs4). The average flow depth in the bend was about $1.5 \mathrm{~m}$, but varies considerably through the bend (Fig. 5). The ratios $R_{a p} / B_{a p}=0.7$ and $R_{a p} / H_{a p}=9.2$ indicate that this is a sharply curved bend.

Fig. 5(b) shows that the bed morphology varies throughout the bend: crs 2 and crs3 have a compound channel appearance that is related to the zones of horizontal flow recirculation, whereas the other cross-sections have morphologies that are more typical of single-thread rivers. Steep outer banks occur downstream of the bend apex. Fig. 5(b) also shows the transverse profile functions with one degree of freedom that have been fitted to the measured bed topography according to Eq. (2), whereas Fig. 5(b) show the corresponding evolution through the bend of the scour factor $A / R$. Similarly, Fig. 5(a) shows the measured velocity distribution and the transverse profile functions fitted to them. The influence of the rightturning upstream bend is clearly visible in the transverse profiles of the bed topography and the velocity. The measured velocities at crs3 (see Fig. 5), reveal flow in the upstream direction which is a signature of the horizontal flow recirculation zone. 
a) Tollense River bend overview

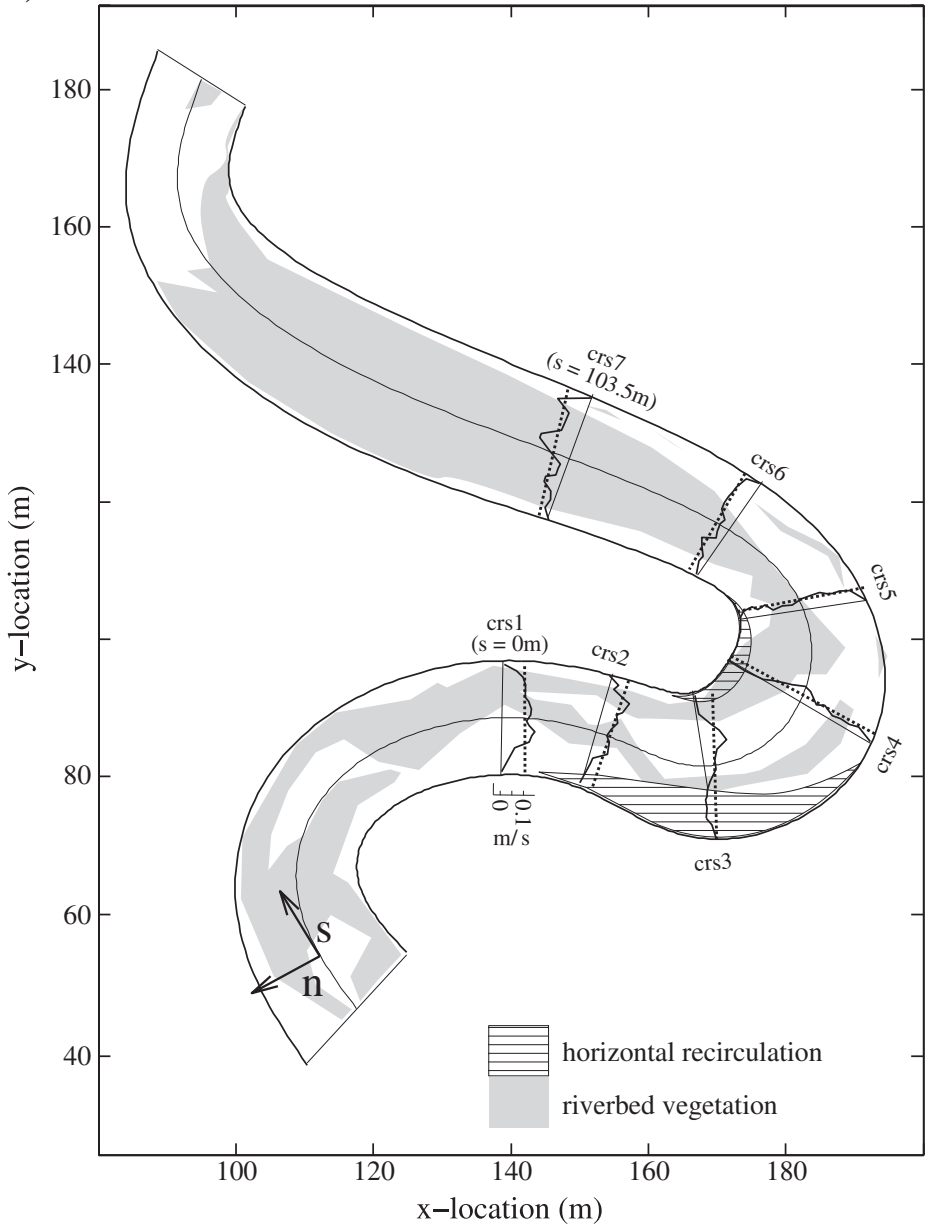

d) channel depth $H(\mathrm{~m})$

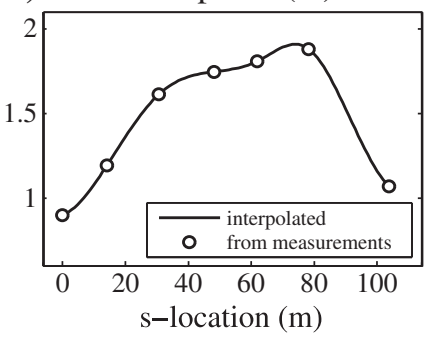

e) channel width $B(\mathrm{~m})$

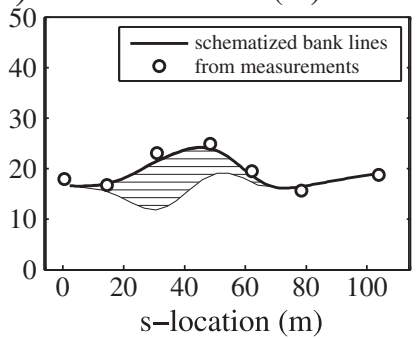

b) bed-elevation (m)

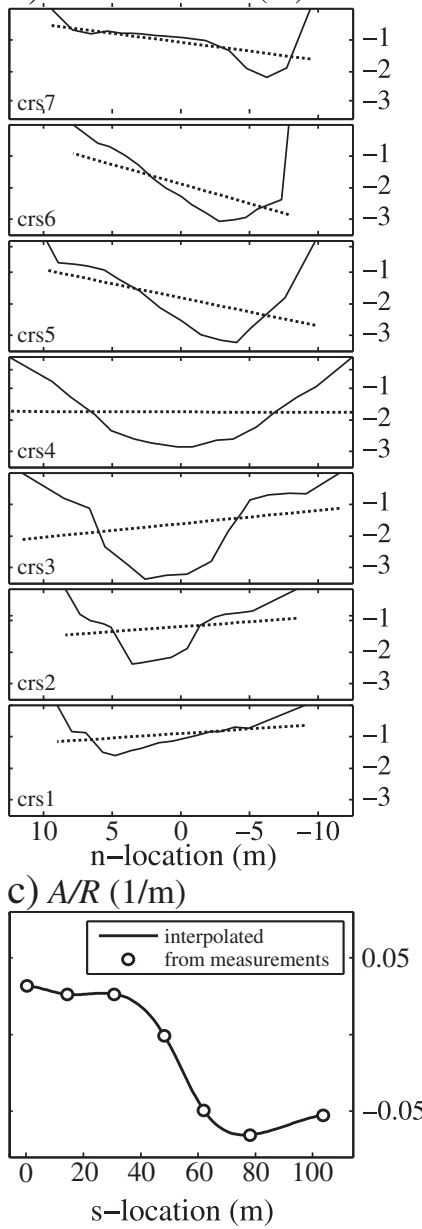

f) friction factor $C f(-)$

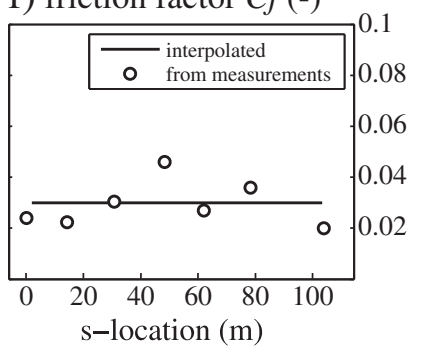

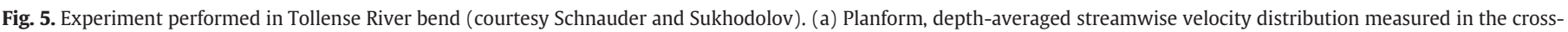

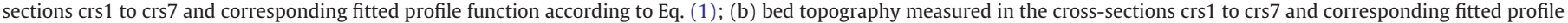

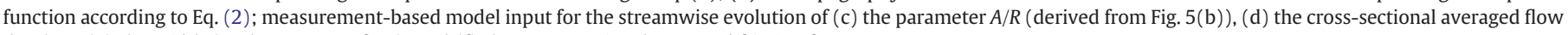
depth $H$; (e) the width (at the water surface); and (f) the cross-sectional averaged friction factor.

For the simulation of this case the measured velocity distribution at crs1 was imposed at the upstream boundary according to Eq. (1). The secondary flow value at the upstream boundary was computed as $\left\langle v_{s} v_{n}\right\rangle_{\infty} / U^{2}=f c t\left(\beta\left(\alpha_{s, c r s 1}\right)\right) \cdot\left\langle v_{s} v_{n}\right\rangle_{0} / U^{2}$. Moreover, the simulations took into account the gradual variations of the width (including the horizontal recirculation zones) and the depth, by means of the smoothed interpolation curves shown in Fig. 5(d) and (e) similarly to the method used for the Polblue Creek bend 3 simulation.

\section{Analysis of processes governing the velocity redistribution}

As indicated in the model description (Section 2), the secondary flow is of particular importance with respect to the velocity redistribution and with respect to the effect and relevance of nonlinear hydrodynamic interactions. Fig. 6 (left column) compares the measured evolution of the width averaged secondary flow strength around the bend to simulations with the nonlinear hydrodynamic model and to simulations with the linear mild-curvature formulation of this model.

The width averaged secondary flow strength is defined as

$\tilde{I}=\frac{1}{B H} \int_{-B / 2}^{B / 2} \sqrt{\left\langle\left(\frac{v_{n}-U_{n}}{U}\right)^{2}\right\rangle} \cdot \operatorname{sign}\left(v_{n, \text { surface }}\right) d n$

The brackets \langle\rangle indicate depth-averaged values. Notice that this parameter remains valid in straight reaches where $R^{-1}=0$. The addition of $\operatorname{sign}\left(v_{n, \text { surface }}\right)$ allows accounting for the sense of rotation of the secondary flow cell. Averaging the secondary flow over the width of the river, allows us to get a qualitative idea about the secondary flow 


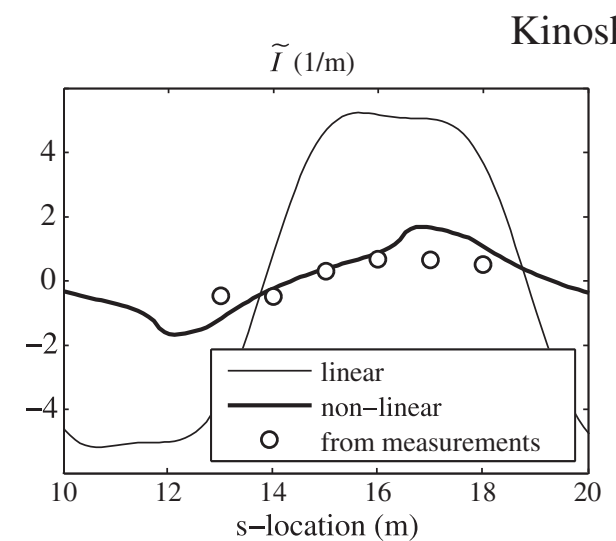

\section{Kinoshita flume}
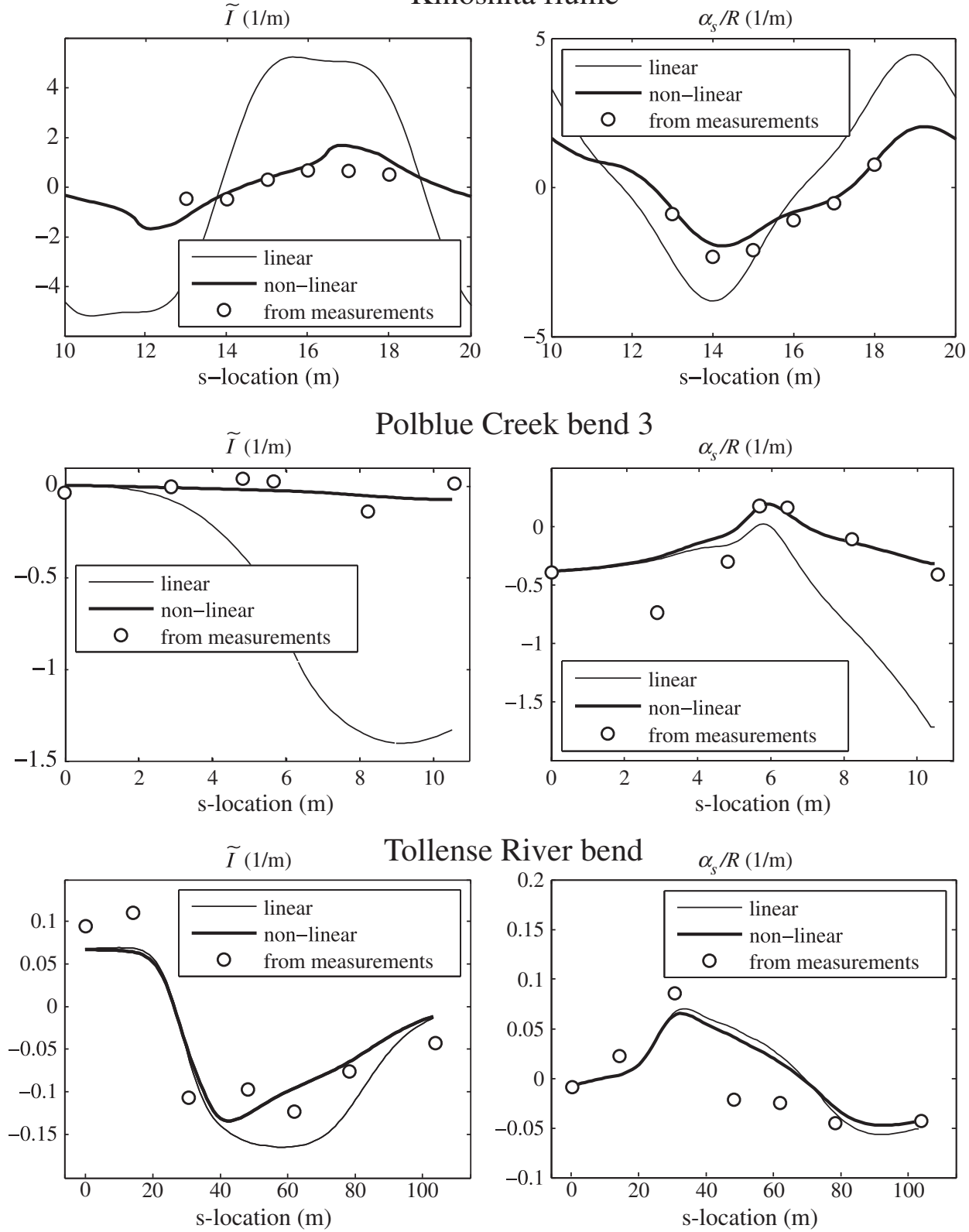

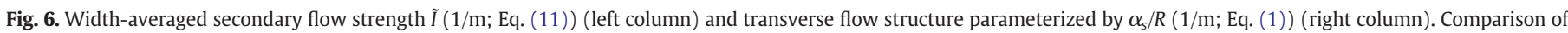

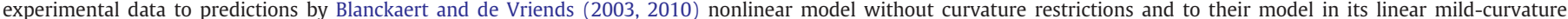
formulation.

strength through the bend as local features which appear on less than the width scale are filtered out.

For all three cases the linear model predicts higher absolute values of the width averaged secondary flow than the nonlinear model. Nonlinear hydrodynamic effects reduce the secondary flow II by as much as $79 \%$, $95 \%$ and $27 \%$ in the three respective cases. For all cases, the nonlinear model predictions agree satisfactorily with the experimental data.

Fig. 6 (right column) compares the streamwise velocity distribution inferred from the measurement to simulations with the nonlinear and linear models, respectively. In line with the observations on the secondary flow, the nonlinear model simulates satisfactorily the global velocity redistribution for all three cases. The linear model fails dramatically for the Polblue bend with values that deviate by an order of magnitude from the measurements, and shows errors of about $100 \%$ for the Kinoshita flume. Only for the Tollense bend, the linear model provides satisfactory results.
These results indicate that the nonlinear model is a reliable tool for predicting the flow distribution in open-channel bends, irrespective of their curvature. The success of the model for the Tollense bend indicates that, although the flow patterns can become increasingly complex in real meander bends (horizontal recirculation zones, riverbed vegetation, pool riffle sequences), the non-linear hydrodynamic flow model is of practical relevance for the modelling of large scale and long term meander development as it accurately captures the large scale velocity redistribution through the bend. Locally, differences may occur, such as the difference between the measured velocity distribution and the nonlinear model prediction in cross-sections crs 4 and crs5 of the Tollense bend. This difference could well be attributed to the patch of vegetation on the point bar near the inner bank, which causes an outwards skewing of the velocities. Obviously, the reduced-order nonlinear hydrodynamic model cannot account for such features occurring on a spatial scale that is smaller than the channel width. 
The successful simulation of the secondary flow and the velocity redistribution in the three investigated sharp open-channel bends further validates Blanckaert and de Vriend's (2003, 2010) nonlinear hydrodynamic model as a tool to investigate the processes that govern the flow redistribution in sharp river bends. The relative importance of the different processes will be assessed by evaluating the different contributions to the forcing term (Eq. (5)) in the model equation of the velocity distribution (Eq. (3)). The nonlinear and linear models will again be compared to provide further insight in the role of the nonlinear hydrodynamic interactions.
For the Kinoshita flume and the Polblue Creek Fig. 7 clearly reveals that the erroneous linear model predictions of the flow redistribution are essentially due to the pronounced overestimation of the effect of the secondary flow (term III in Eq. (5)), which is erroneously identified as the dominant process with respect to the velocity redistribution. As mentioned before, nonlinear hydrodynamic effects reduce the secondary flow strength in the Tollense bend by $27 \%$ (Fig. 6). Nevertheless, the linear and nonlinear model predictions of the velocity distribution (Fig. 6) are hardly different. This can be explained by the spatial distribution of the forcing terms around the bend: secondary flow
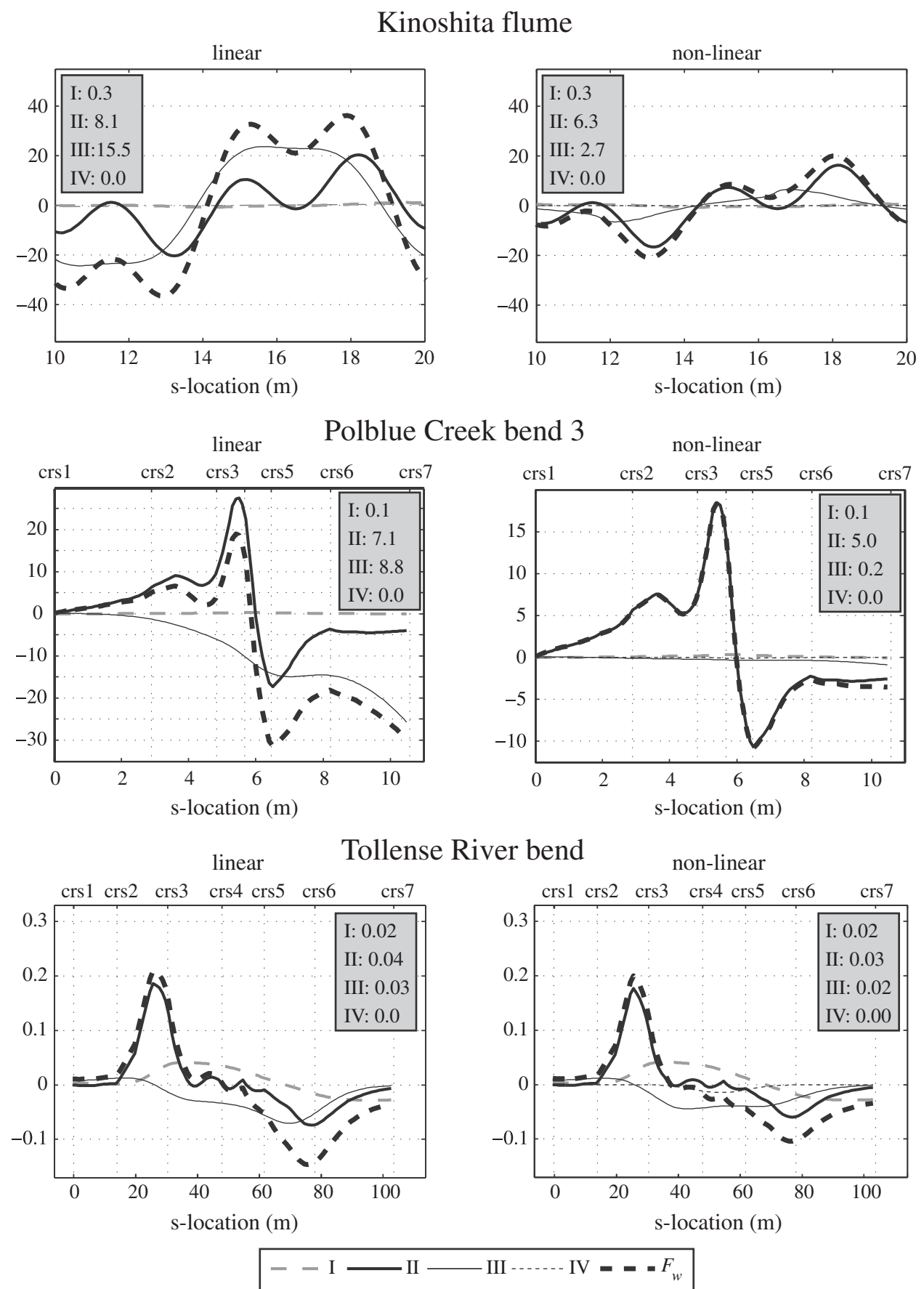

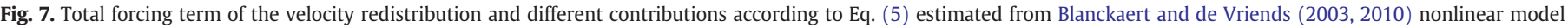

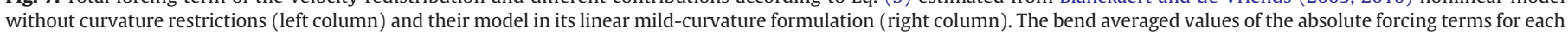
case are included in the shaded rectangle. 
effects are an order of magnitude smaller than the effects of curvature variations in the upstream half of the Tollense bend, and they only become relevant in the downstream half of the bend. Nonlinear hydrodynamic effects also affect the change in curvature mechanism (term II in Eq. (5), see bend-averaged values included in Fig. 7). Again the effect is more pronounced in the Kinoshita flume and the Polblue Creek bend 3, than in the Tollense River bend.

The streamwise change in curvature (term II in Eq. (5)) is the dominant process in all three investigated cases. This confirms the scaling analysis of Blanckaert and de Vriend (2010), which suggested that this process is negligible in mildly curved bends but of leading order of magnitude if $C_{f}^{-1} H / R=0(1)$. This scaling parameter attains values of about 21, 29 and 2 in the Kinoshita, Polblue and Tollense bends, respectively.

Velocity redistribution by the secondary flow is a process of dominant order of magnitude in all three cases. The scaling analysis of Blanckaert and de Vriend (2010) suggested that this process is of dominant order of magnitude in narrow rivers $B / H<10$, but negligible in shallow ones $B / H>50$. The aspect ratio for the Kinoshita flume, Polblue Creek and the Tollense River are 4.2, 2.3 and 12.6 respectively. This means that although nonlinear hydrodynamic interactions considerably reduce secondary flow effects in sharply curved river bends, they remain of dominant order of magnitude in bends that are not very shallow.

Topographic steering of the flow (term I in Eq. (5)) is obviously negligible in the Kinoshita flume with horizontal bed. It is a process of dominant order of magnitude in the Tollense bend, but also negligible in the Polblue bend. This seemingly contradicts the scaling analysis of Blanckaert and de Vriend (2010), which suggested that this process is never negligible. Their scaling analysis was based on values of the scour parameter $A$ in the range of 2.5 to 6 , however, which is typical for alluvial rivers (Ikeda et al., 1981; Odgaard, 1981). The quasi-horizontal bed topography in the Polblue bend leads to a scour factor that is an order of magnitude smaller, and explains why topographic steering is negligible.

The influence of streamwise variations in the transverse bed and water surface slopes (term IV in Eq. (5)) is negligible in all three cases, as predicted by Blanckaert \& de Vriend's scaling analysis.

These results extend the results of Blanckaert (2011), who investigated the asymptotic case of axi-symmetric curved flow (an infinite bend of constant curvature). Blanckaert showed the relative importance of secondary flow and topographic steering as a function of the two control parameters $C_{f}^{-1} H / B$ and $R / B$ and moreover he analyzed the influence of non-linear hydrodynamic effects as a function of these same two parameters. The first parameter, accounting for the roughness and the shallowness, characterizes a river reach, whereas the second parameter quantifies the curvature of individual bends. Although this case of axi-symmetric curved flow is by definition unable to account for curvature changes, its solution can be seen as a first approximation for the importance of secondary flow effects and topographic steering in natural river bends with varying curvature.

As mentioned in the introduction, the secondary flow has two important effects on the flow redistribution. Besides the advective redistribution of momentum analyzed above, the secondary flow also induces a transverse component of the bed shear stress, which conditions the development of a transverse bed slope (Olesen, 1987; Camporeale, et al., 2007) that in its turn leads to topographic steering. Averaged over the bend, the scour factors, $A$, in the Polblue and Tollense bends are about 0.1 and 0.35 , respectively, which is considerably lower than the typical values for alluvial rivers of $A=2.5$ to 6 reported by Ikeda et al. (1981) and Odgaard (1981). These low values may be ascribed to two main causes. The first is the reduction of the secondary flow strength due to non-linear hydrodynamic interactions. The second reason is the high roughness in the vegetated Tollense River $\left(C_{f} \approx 0.03\right)$, which is higher than the typical roughness found in naturally meandering channels ( $C_{f} \approx 0.008$; Crosato, 2008 , Table 7.1). An increase in roughness leads to weaker secondary flow (cf. Blanckaert and de Vriend, 2003, Fig. 4).

\section{Conclusions}

The processes governing the velocity redistribution in sharp meander bends are still poorly understood, which can largely be attributed to the validity range of most meander models (i.e. limited to mildly-curved bends and slow streamwise curvature variations), and also to the scarcity of experimental data in sharp bends. This paper provided new insight in hydrodynamic processes occurring in sharp river bends based on numerical simulations of three recent experiments by means of Blanckaert and de Vriend's (2003, 2010) reduced-order nonlinear model without curvature restrictions. These three experiments concerned very sharply curved open-channel flows in configurations with different characteristics. The Kinoshita laboratory flume had a narrow rectangular cross-section and smooth boundaries, the even narrower Polblue bend was characterized by the quasi-absence of secondary flow, and the Tollense had marked horizontal recirculation zones and patches of riverbed vegetation.

Blanckaert and de Vriend's nonlinear model includes the following processes that contribute to the velocity redistribution in bends: topographic steering, effects of streamwise variations in river curvature and effects of secondary flow. Moreover it accounts for nonlinear hydrodynamic interactions that reduce the secondary flow strength. The model successfully simulated the global mean flow redistribution and the characteristics of the secondary flow in all three experiments, which further validated the model as a tool to investigate the processes governing the global flow redistribution. The results suggest that the global flow redistribution is primarily governed by topographic steering, curvature changes and secondary flow, in a broad range of different configurations, including mildly to sharply curved bends, narrow to shallow bends, smooth to rough bends, bends with additional complexities such as horizontal recirculation zones or patches of riverbed vegetation. The relative importance of these three dominant processes is case dependent, and essentially controlled by the parameters $C_{f}^{-1} H / B, R / B$ and streamwise variations in curvature, $\partial R^{-1} / \partial s$ which are determined by the river planform. The first parameter characterizes a river reach, whereas the second and third parameters are characteristics of individual bends.

Major differences exist between the processes governing the velocity redistribution in mildly and sharply curved bends. First, velocity redistribution induced by curvature variations is negligible in mildly curved bends, but was found to be the dominant process in the three investigated sharp bends. These results confirm the scaling analysis of Blanckaert and de Vriend (2010), which suggested that flow redistribution induced by streamwise curvature variations scales with the control parameter $C_{f}^{-1} H / R$. This result is relevant, because most meander models are based on the assumption of weakcurvature variations and therefore intrinsically unable to represent accurately the velocity redistribution in sharp river bends. Second, nonlinear hydrodynamic processes play a dominant role in sharp bends, as revealed by comparison of predictions with Blanckaert \& de Vriend's nonlinear hydrodynamic model to predictions with their model in its linear mild-curvature formulation. Linear models were not as accurate in predicting the secondary flow strength in the three investigated sharp bends. For the Tollense the linear model provided the correct order of magnitude, however for the Kinoshita flume andd the Polblue Creek it overpredicted the secondary flow strength by an order of magnitude, and falsely identified the secondary flow as the dominant process governing the velocity redistribution, ultimately leading to unsatisfactory predictions of the velocity redistribution. The inclusion of nonlinear hydrodynamic interactions in the nonlinear model reduces the growth of the secondary flow with increasing curvature. This mechanism, which Blanckaert called the saturation of the secondary flow, was also demonstrated by van Balen et al. (2011)) using a Large Eddy Simulation model applied to a wide range of axi-symmetric flow cases. This saturation of the secondary flow is accompanied by a reduction in the velocity redistribution 
induced by the secondary flow, as well as a reduction in the transverse bed slope induced by the near-bed secondary flow velocities. This reduced transverse bed slope reduces the effect of topographic steering.

It should be recalled that this paper focused on the hydrodynamic processes occurring in sharp open-channel bends. The nonlinear hydrodynamic model has to be coupled to models for the bed morphology and for the bank migration that are valid in the sharpcurvature range, in order to obtain a model for meander dynamics without curvature restrictions.

\section{Acknowledgements}

The Dutch Technology Foundation (STW, applied science division of NWO) is acknowledged for funding the PhD research of the first author under grant DCB.7780. The support of Deltares is also gratefully acknowledged. The development of the nonlinear hydrodynamic model by the second author was funded by the Swiss National Science Foundation (SNF) under grants 2100-052257, 2000059392, 2100-066992, 20020-103932, and 200020-119835. The second author further acknowledges funding by Chinese Academy of Sciences fellowship for young international scientists under grant 2009YA1-2 and by the Sino-Swiss Science And Technology Cooperation for the joint research project GJH20908. The authors thank Jorge Abad for the measurement data from the Kinoshita Flume, Rachel Nanson for the measurement data from the Polblue Creek and Ingo Schnauder and Alex Sukhodolov for the Tollense River field data. The acquisistion of the field data of the Tollense River was funded by the Deutsche Forschungsgemeinschaft (DFG) and the Netherlands Organization for Scientific Research (NWO) under grants SU 405/3-1 and DN66-149 in the framework of their bilateral cooperation program. Finally, Mohamed Nabi is thanked for reviewing the manuscript and Hanneke Nijhof is thanked for help with the production of the figures.

\section{Appendix A. Supplementary data}

Supplementary data associated with this article can be found in the online version, at doi:10.1016/j.geomorph.2011.04.049. These data include Google maps of the most important areas described in this article.

\section{References}

Abad, J.D., Garcia, M.H., 2009. Experiments in a high-amplitude kinoshita meandering channel: 1 . implications of bend orientation on mean and turbulent flow structure. Water Resources Research 45, W02401. doi:10.1029/2008WR007016.

Blanckaert, K., 2009. Saturation of curvature-induced secondary flow, energy losses, and turbulence in sharp open-channel bends: laboratory experiments, analysis, and modeling. Journal of Geophysical Research 114, F03015. doi:10.1029/ 2008JF001137.

Blanckaert, K., 2010. Topographic steering, flow recirculation, velocity redistribution, and bed topography in sharp meander bends. Water Resources Research 46, W09506. doi:10.1029/2009WR008303.

Blanckaert, K., 2011. Hydrodynamic processes in sharp meander bends and their morphological implications. Journal of Geophysical Research 116, F01003. doi:10.1029/2010JF001806.

Blanckaert, K., De Vriend, H.J., 2003. Nonlinear modeling of mean flow redistribution in curved open channels. Water Resources Research 39, ESG61-ESG614.

Blanckaert, K., de Vriend, H.J., 2010. Meander dynamics: a nonlinear model without curvature restrictions for flow in open-channel bends. Journal of Geophysical Research 115, F04011. doi:10.1029/2009JF001301.

Bolla Pittaluga, M., Nobile, G., Seminara, G., 2009. A nonlinear model for river meandering. Water Resources Research 45, W04432. doi:10.1029/2008WR007298.
Boussinesq, J., 1868. Mémoire sur l'influence de frottement dans les mouvements réguliers des fluides; xii - essai sur le mouvement permanent d'un liquide dans un canal horizontal axe circulaire. Journal de Mathématiques Pures et Appliquées 13.

Camporeale, C., Perona, P., Porporato, A., Ridolfi, L., 2007. Hierarchy of models for meandering rivers and related morphodynamic processes. Reviews of Geophysics 45. doi:10.1029/2005RG000185.

Crosato, A., 2008. Analysis and Modelling of River Meandering. Ph.D. Thesis. Delft University of Technology.

da Vinci, L., 1503-1508. Codex Arundel 263, 216 V.

de Vriend, H.J., 1977. A mathematical model of steady flow in curved shallow channels. Journal of Hydraulic Research 15, 37-54.

de Vriend, H.J., 1981. Steady flow in shallow channel bends (Technical Report Rep.) Fluid Mech. Lab., Dep. of Civ. Eng., Delft University of Technology, pp. 81-83.

Dietrich, W.E., Smith, J.D., 1983. Influence of the point bar on flow through curved channels. Water Resources Research 19, 1173-1192.

Engelund, F., 1974. Flow and bed topography in channel bends. Journal of the Hydraulics Division 100, 1631-1648.

Fargue, L., 1868. Étude sur la corrélation entre la configuration du lit et la profondeur d'eau dans les rivières á fond mobile. Annales Des Ponts Et Chaussées.

Friedkin, J.F., 1945. A Laboratory Study of the Meandering of Alluvial Rivers. (Technical Report) U.S. Waterways Experiment Station, Mississippi.

Ikeda, S., 1975. On secondary flow and bed profile in alluvial curved open channel. Proc. XVIth IAHR Congress, Sao Paulo (Paper B-14).

Ikeda, S., Parker, G., Sawai, K., 1981. Bend theory of river meanders. - 1. linear development. Journal of Fluid Mechanics 112, 363-377.

Imran, J., Parker, G., Pirmez, C., 1999. A nonlinear model of flow in meandering submarine and subaerial channels. Journal of Fluid Mechanics 400, 295-331.

Johannesson, H., Parker, G., 1989a. Secondary flow in mildly sinuous channel. Journal of Hydraulic Engineering 115, 289-308.

Johannesson, H., Parker, G., 1989b. Velocity redistribution in meandering rivers. Journal of Hydraulic Engineering 115, 1019-1039.

Legleiter, C.J., Kyriakidis, P.C., 2006. Forward and inverse transformations between cartesian and channel-fitted coordinate systems for meandering rivers. Mathematical Geology 38. doi:10.1007/s11004-006-9056-6.

Leopold, L.B., Wolman, M.G., 1960. River meanders. Geological Society of America Bulletin 71, 769-794.

Nanson, R.A., 2010. Flow fields in tightly curving meander bends of low width-depth ratio. Earth Surface Processes and Landforms 35, 119-135. doi:10.1002/esp. 1878.

Nanson, R.A., Nanson, G.C., Huang, H.Q., 2010. The hydraulic geometry of narrow and deep channels; evidence for flow optimisation and controlled peatland growth. Geomorphology 117, 143-154. doi:10.1016/j.geomorph.2009.11.021.

Nelson, J.E., 1990. The initial instability and finite-amplitude stability of alternate bars in straight channels. Earth Science Reviews 29, 97-115. doi:10.1016/0012-8252(0) 90030-Y.

Odgaard, A.J., 1981. Transverse bed slope in alluvial channel bends. Journal of the Hydraulics Division, ASCE 107, 1677-1694.

Olesen, K.W., 1987. Bed topography in shallow river bends. Ph.D. thesis. Delft University of Technology.

Parker, G., Diplas, P., Akiyama, J., 1983. Meander bends of high amplitude (channel migration). Journal of Hydraulic Engineering ASCE 109, 1323-1337.

Rodi, W., 1980. Turbulence Models and Their Application in Hydraulics. International Association for Hydraulic Research, Delft.

Rozovskii, I.L., 1957. Flow of Water in Bends of Open Channels. Academy of Sciences of the Ukrainian SSR. Israel Program for Scientific Translation, 1961.

Rüther, N., Olsen, N.R.B., 2007. Modelling free-forming meander evolution in a laboratory channel using three-dimensional computational fluid dynamics. Geomorphology 89, 308-319. doi:10.1016/j.geomorph.2006.12.009.

Schnauder, I., Sukhodolov, A.N., 2011. Flow in a tightly curving meander bend: effects of seasonal changes in aquatic macrophyte cover. (submitted to) Earth Surface Processes and Landforms.

Thomson, J., 1876. On the origin of windings of rivers in alluvial plains, with remarks on the flow of water round bends in pipes. Proceedings of the Royal Society of London 25, 5-8.

van Balen, W., Uijttewaal, W.S.J., Blanckaert, K. 2011. A parameter study on curved open-channel flows by means of large-eddy simulation. (submitted to) Journal of Geophysical Research.

van Bendegom, L., 1947. Some considerations on river morphology and river improvement. De Ingenieur 59, B1-B11.

Vardy, A., 1990. Fluid Principles. McGraw-Hill.

Yeh, K.C., Kennedy, J.F., 1993. Moment model of nonuniform channel-bend flow I: fixed beds. Journal of Hydraulic Engineering ASCE 119, 776-795.

Zimmermann, C., Kennedy, J.F., 1978. Transverse bed slopes in curved alluvial streams. J. Hydraul. Div.: Proc. ASCE, 104, pp. 33-48.

Zolezzi, G., Seminara, G., 2001. Downstream and upstream influence in river meandering. part 1 . general theory and application to overdeepening. Journal of Fluid Mechanics 438, 183-211. 